\title{
Article \\ Health Effect of N-Nitroso Diethylamine in Treated Water on Gut Microbiota Using a Simulated Human Intestinal Microbiota System
}

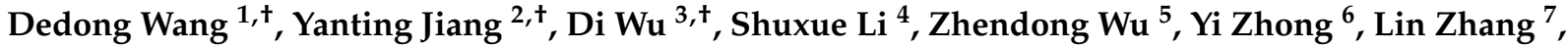 \\ Chongshan Guo ${ }^{6}$, Xiaotong Li ${ }^{6}$, Lili Sun ${ }^{8}$, Qin $\mathrm{Li}^{6}$, Jinhua Zhou ${ }^{9}$ and Weiyun $\mathrm{He}^{7 \text {,* }}$
}

check for

updates

Citation: Wang, D.; Jiang, Y.; Wu, D.; Li, S.; Wu, Z.; Zhong, Y.; Zhang, L.; Guo, C.; Li, X.; Sun, L.; et al. Health Effect of N-Nitroso Diethylamine in Treated Water on Gut Microbiota

Using a Simulated Human Intestinal Microbiota System. Processes 2022, 10, 438. https://doi.org/10.3390/ pr10030438

Academic Editor: Chi-Fai Chau

Received: 24 January 2022

Accepted: 20 February 2022

Published: 22 February 2022

Publisher's Note: MDPI stays neutral with regard to jurisdictional claims in published maps and institutional affiliations.

Copyright: (C) 2022 by the authors. Licensee MDPI, Basel, Switzerland. This article is an open access article distributed under the terms and conditions of the Creative Commons Attribution (CC BY) license (https:// creativecommons.org/licenses/by/ $4.0 /)$.
1 Department of Radiological Protection, Guangzhou Center for Disease Control and Prevention, Guangzhou 510440, China; gzcdc_wangdd@gz.gov.cn

2 Department of Clinical Medicine, Clinical Medical School, Guangzhou Medical University, Guangzhou 510440, China; tt931777978@163.com

3 Department of Noncommunicable Disease Control and Prevention, Guangzhou Center for Disease Control and Prevention, Guangzhou 510440, China; gzcdc_wud@gz.gov.cn

4 Department of Student Affairs, Guangzhou Medical University, Guangzhou 510440, China; gzshuxuel@126.com

5 Department of Environmental Hygiene, School of Public Health, Southern Medical University, Guangzhou 510440, China; dgivbaf@126.com

6 Department of Environmental Health, Guangzhou Center for Disease Control and Prevention, Guangzhou 510440,China; gzcdc_zhongy@gz.gov.cn (Y.Z.); gzcdc_guocs@gz.gov.cn (C.G.); gzcdc_lixt@gz.gov.cn (X.L.); gzcdc_liq@gz.gov.cn (Q.L.)

7 Director Office, Guangzhou Center for Disease Control and Prevention, Guangzhou 510440, China; gzcdc_zhangl@gz.gov.cn

8 Executive Office for Managing Action in Disease Control and Prevention, Guangzhou Center for Disease Control and Prevention, Guangzhou 510440, China; gzcdc_sunll@gz.gov.cn

9 Department of Disinfection and Vector Control, Guangzhou Center for Disease Control and Prevention, Guangzhou 510440, China; gzcdc_zhoujh@gz.gov.cn

* Correspondence: gzcdc_hewy@gz.gov.cn

+ These authors contributed equally to this work.

Abstract: Chlorination disinfection byproducts (CDBPs) can exert adverse human health effects. Many toxicology-based studies confirmed the health hazards of CDBPs, but little research has been done on gut microbiome. We explored the effect of CDBPs on intestinal microbiota in the Simulator of the Human Intestinal Microbial Ecosystem (SHIME). The results showed that CDBPs slightly inhibited the production of short-chain fatty acids, and the abundance of Actinobacteria decreased in the transverse colon and descending colon. The abundance of Proteobacteria increased in the ascending colon and descending colon, while it decreased in the transverse colon. The abundance of Firmicutes decreased in both the ascending colon and descending colon. In particular, the abundance of Lachnospiraceae members, Bilophila, Oscillospira, Parabacteroides, Desulfovibrio, and Roseburia increased in the ascending colon, while the abundance of Sutterella, Bacteroides, Escherichia, Phascolarctobacterium, Clostridium, Citrobacter, and Klebsiella increased in the descending colon. The Shannon index differed significantly in both the ascending colon and descending colon before and after exposure. Overall, we demonstrate the feasibility of applying the SHIME model to studying the effects of intestinal toxicity on health of chlorinated by-products. The findings of this study improve our understanding of the health impact of CDBPs on the intestinal microbiota and better control of CDBPs in treated water is recommended.

Keywords: health effect; treated water; N-nitroso diethylamine; gut microbiota; chlorination disinfection by-products 


\section{Introduction}

The safety of drinking water has long been concerned due to its important influence on human health. However, the specific relationship between water purification byproducts and human health remains unclear. Chlorine or chlorine dioxide is typically used as the primary disinfectant of drinking water disinfection with monochloramine as a residual disinfectant [1]. Chlorinated disinfection byproducts (CDBPs) of disinfection can form from substitution, addition, and oxidation reactions between chemical disinfectants and naturally occurring organic matter in the water. Chlorine can oxidize organic matter to trihalomethanes and other chlorinated disinfection byproducts such as haloacetic acid [2-4]. Trihalomethanes include trichloromethane, bromodichloromethane, chlorodibromomethane, and tribromomethane [5]. Toxicological and epidemiological studies have shown that exposure to some CDBPs can exert adverse health effects such as reproductive and developmental defects and potential genotoxicity [6,7]. Some CDBPs can also dysregulate the immune system [8-11], and haloacetic acid can damage DNA in rat ovary cells [12].

Methods to assess the toxicity of CDBPs have been developed, but the developmental toxicity of these compounds is still poorly characterized. CDBPs have been evaluated using zebrafish embryo bioassays [13] or colorimetry to measure the concentrations of monochloramine and free chlorine in water [14]. The contribution of volatile CDBPs to the developmental toxicity of CDBP compounds is considered negligible [15]. Testing the mutagenicity or genotoxicity of CDBPs is mainly conducted by the Salmonella mutagenesis test, umu chromotest, or SOS chromotest [16,17]. Cell stability in the culture medium is a key parameter for in vitro toxicity assessments of disinfection byproducts [18], but the complexity and cost of CDBPs investigations have limited the development of effective and comprehensive methods for assessing human toxicity.

Gut microbiota, a large diversity and quantity of microbes in the intestines, is inherently involved in human health. Alterations in the structure of the bacterial community, namely a decrease in probiotics or an increase in pathogenic bacteria in the intestinal tract, can lead to metabolic disorders. They can also promote the progression of diseases and conditions such as type 2 diabetes mellitus, high salt-induced hypertension, and osteoarthritis [19-23]. It is important to identify compounds and species-specific responses in the gut microbiota. However, the specific effects of CDBPs on the intestinal flora of the host digestive system remain unclear. Exposure to environmental pollutants can dysregulate intestinal microbial communities [24-26] in a compound-specific manner. For example, ingestion of polychlorinated biphenyls can reduce the levels of Proteobacteria [27] and 2,3,7,8-tetrachlorodibenzofuran can change the Firmicutes / Bacteroidetes ratio in the mouse gut, inducing host metabolic disorders $[24,28]$. However, only a few studies to date have disclosed the impact of CDBPs exposure on the gut microbiome $[29,30]$. Considering the CDBPs' diversity, limited human resources, and research expense, it is impossible to evaluate them all. Therefore, we studied specific variations in intestinal flora to evaluate the health effects of toxicity of CDBPs.

Multiple in vitro systems have been developed to characterize the metabolism of environmental pollutants in the intestine. The Simulator of the Human Intestinal Microbial Ecosystem (SHIME) is one of them, which includes a simulated glass jar, a peristaltic pump, and a magnetic stirrer [31]. SHIME has been used to study the absorption and metabolism of environmental pollutants by gut microbiota owing to its effective simulation of human digestion and the intestinal microecological environment [31,32], including substances such as chlorpyrifos [33] and iron [34].

We hypothesized that CDBPs can alter the structure and metabolism of human intestinal flora. We thus used SHIME with human intestinal microorganisms to assess the health effects of CDBPs from chlorinated water. This also enabled us to evaluate the feasibility of using SHIME to study the intestinal toxicity of CDBPs. 


\section{Materials and Methods}

\subsection{Preparation of Nutrient Solution and Digestive Solution}

The nutrient solution consists of arabinogalactan $(1 \mathrm{~g} / \mathrm{L})$, pectin $(2 \mathrm{~g} / \mathrm{L})$, xylan $(1 \mathrm{~g} / \mathrm{L})$, starch $(3 \mathrm{~g} / \mathrm{L})$, glucose $(0.4 \mathrm{~g} / \mathrm{L})$, peptone $(1 \mathrm{~g} / \mathrm{L})$, yeast extract $(3 \mathrm{~g} / \mathrm{L})$, cysteine $(0.5 \mathrm{~g} / \mathrm{L})$, sodium bicarbonate $(1 \mathrm{~g} / \mathrm{L})$, and Twain $80(1 \mathrm{~g} / \mathrm{L})$, which was dissolved in $2 \mathrm{~L}$ distilled water and autoclaved at $121^{\circ} \mathrm{C}$ for $25 \mathrm{~min}$. The nutrient solution was maintained at $4{ }^{\circ} \mathrm{C}$ until subsequent analysis after cooling. The digestive solution included gastric juice and pancreatic juice. The gastric juice was prepared by dissolving $2 \mathrm{~g}$ sodium chloride and $3.2 \mathrm{~g}$ pepsin in sterile water, then adding $7 \mathrm{~mL} \mathrm{36.5 \%} \mathrm{concentrated} \mathrm{hydrochloric} \mathrm{acid} \mathrm{at} \mathrm{a} \mathrm{fixed}$ volume of $1000 \mathrm{~mL}$. Small intestinal juice was prepared by dissolving $6 \mathrm{~g}$ bile salt, $0.9 \mathrm{~g}$ trypsin, and $12.5 \mathrm{~g}$ sodium bicarbonate in sterilized water. The volume was fixed to $1000 \mathrm{~mL}$, and the two solutions were labeled and maintained at $4{ }^{\circ} \mathrm{C}$ until subsequent analysis.

\subsection{Preparation of Fecal Inoculation Solution}

Two healthy hosts, aged 20-25 years, who had not received antibiotic treatments during the previous 6 months and had normal intestinal motility were selected. Fecal samples were immediately stored in a sterile sealed bag before being transferred to the laboratory. A total of $40 \mathrm{~g}$ of fresh feces were weighed and added to $200 \mathrm{~mL}$ of sterile phosphatebuffered saline, then set aside for $10 \mathrm{~min}$. The obvious precipitates at the bottom were discarded and the upper turbid liquid was centrifuged at $1000 \times g \mathrm{rpm}$ and $4{ }^{\circ} \mathrm{C}$ for $10 \mathrm{~min}$. 50 milliliters of the upper liquid were placed in a labeled centrifuge tube and kept at $-80{ }^{\circ} \mathrm{C}$ until subsequent analysis. This study has been approved by the Ethics Committee of Guangzhou Center for Disease Control and Prevention and the ethical approved project identification code is GZCDC 2018013.

\subsection{Components of the SHIME Model}

The SHIME model consists of the digestion body and controllers of time, $\mathrm{pH}$, temperature, and air path. The body of the digestive system includes a simulated glass jar, a peristaltic pump, and a magnetic stirrer. The digestive system simulator includes five laminated glass jars that simulate the stomach, small intestine, ascending colon, transverse colon, and descending colon. The capacity of the three colonic canisters $(1000 \mathrm{~mL})$ is larger than that of the stomach and small intestine simulation canisters $(500 \mathrm{~mL})$, which are equipped with a triangular magnetic agitator. Each laminated glass jar has a threaded hole in the lid for fitting adapters to a silicone or polytetrafluoroethylene tube. Three colonic irrigation tubes are placed on respective magnetic stirrers to simulate physiological digestion. The feed liquid is transported quantitatively through the periodic opening and closing of the peristaltic pump. The time control module is composed of time-controlled switches corresponding to each peristaltic pump, which turns on at the set time to pump nutrient liquid or digestive liquid into the system and simulate digestion in each tank until the preset time and then pump into the next tank. The time-controlled switch can realize the automatic control of the SHIME model. The $\mathrm{pH}$ control plate includes a $\mathrm{pH}$ electrode, a $\mathrm{pH}$ controller, acid solution (hydrochloric acid), and alkaline solution (sodium hydroxide) for regulation. The electrode and controller were purchased from Consort Belgium (Brussels, Belgium). The $\mathrm{pH}$ electrode used in this experiment was a long electrode that monitored the $\mathrm{pH}$ status of each colonic canister for $24 \mathrm{~h}$ continuously. The $\mathrm{pH}$ value of colon could be monitored by electrodes in real time; when the $\mathrm{pH}$ was out of range, the $\mathrm{pH}$ controller opened the solenoid valve to deliver the acid or base into the colon and stabilize the $\mathrm{pH}$. An additional polytetrafluoroethylene valve was added in the acid and alkali flow channel to control the flow rate.

The temperature was controlled by a constant temperature circulating water bath and a refrigerator, and the external circulation of the water bath was connected to the colonic tank interlayer to maintain a constant temperature of $37^{\circ} \mathrm{C}$ in the model. Refrigerator stores autoclave the nutrient solution and digestive solution. The door of the refrigerator is connected directly to the gastric tube by a silica gel tube to achieve better refrigeration. 
The air path controller aerates nitrogen to the model to maintain the anaerobic environment in this in vitro digestion model. Nitrogen gas cylinders were connected to the gastric canister and nitrogen gas was supplied directly to the interlayer tanks through silica gel tubes. The end of the silicone tube was placed into a beaker containing sterile water to block the inflow of external gas and an oxygen-free environment.

\subsection{Operation of the SHIME Model}

We started to add nutrient solution and fecal inoculation solution (ascending colon tank/descending colon tank: $500 \mathrm{~mL}+50 \mathrm{~mL}$, transverse colon tank: $800 \mathrm{~mL}+80 \mathrm{~mL}$ ) after connecting the instrument. The control sample was the fluid in the colon on the first 14th day. The sample was considered as the experimental group after feeding of CDBPs on 14 days. Two hundred milliliters of nutrient liquid and $100 \mathrm{~mL}$ of gastric juice were pumped into the model every $8 \mathrm{~h}$. The magnetic stirrer under the gastric juice was operating to simulate gastric digestion. The mixture was emptied into the small intestine jar through a peristaltic pump after digestion in the stomach jar for $2 \mathrm{~h}$, and $100 \mathrm{~mL}$ pancreatic juice was pumped at the same time with corresponding stirrer open. The contents were transferred to the colon after $4 \mathrm{~h}$ of digestion in the small intestine. The contents of the three canisters in the ascending, transverse, and descending colon were maintained at 500, 800, and $500 \mathrm{~mL}$, respectively. The $\mathrm{pH}$ in the three colon cans was set to 5.6-5.9, 6.1-6.4, and 6.6-6.9, respectively. When the $\mathrm{pH}$ was out of the specified range, the $\mathrm{pH}$ controller received electrode feedback, and $0.5 \mathrm{~mol} / \mathrm{L}$ hydrochloric acid or sodium hydroxide was automatically added to adjust the $\mathrm{pH}$. The contents of each reactor were transferred by peristaltic pump and nitrogen was aerated into the reactor at regular intervals three times a day, $10 \mathrm{~min}$ each time. Every 3 days, aliquots $(8-10 \mathrm{~mL})$ were taken from the ascending colon, transverse colon, and descending colon at 19:30. Each colon sample was then aliquoted between three new $1 \mathrm{~mL}$ EP tubes for replication. The remaining samples were stored at $-80^{\circ} \mathrm{C}$. The EP tubes were centrifuged at $4{ }^{\circ} \mathrm{C}$ at $6000 \times g \mathrm{rpm}$ for $10 \mathrm{~min}$. After centrifugation, the supernatant was divided into new EP tubes, labeled and refrigerated at $-80{ }^{\circ} \mathrm{C}$ for subsequent analysis. The supernatant was used to assess production of short-chain fatty acids (SCFAs) by the intestinal microflora. Bacterial precipitation was used to extract DNA for subsequent high-throughput sequencing of 16S rRNA genes.

\subsection{Sequencing Analysis of $16 S$ rRNA Gene Amplicon}

All DNA was extracted in accordance with the instructions of E.Z.N.A. SOIL Kit (Omega Bio-Tek, Norcross, GA, USA), and DNA concentration and purity were detected by NanoDrop2000. After completing, we prepared the 1\% agarose gel. Agarose gel electrophoresis (electrophoresis condition: $5 \mathrm{~V} / \mathrm{cm}, 20 \mathrm{~min}$ ) was performed to detect the quality of extracted DNA. PCR amplification of the V3-V4 variable region was performed using 338F (5'-ACTCCTACGGGAGCAGCAG-3') and 806R (5'-GGACTACHVGGGTWTCTAAT$\left.3^{\prime}\right)$ as primers. PCR products were recycled using $2 \%$ agarose Gel and purified using AxyPrep DNA Gel Extraction Kit (Axygen Biosciences, Union City, CA, USA), followed by Tris- $\mathrm{HCl}$ elution and $2 \%$ agarose electrophoresis. Quantification was performed using the Quantifluor-ST (Promega, Madison, WI, USA). The purified amplified fragments were used to construct the PE2 $\times 300$ library according to the standard operating procedures of Illumina Miseq (Illumina, San Diego, CA, USA).

\subsection{Extraction of CDBPs of Drinking Water}

A total of $200 \mathrm{~L}$ water was collected from each of the three waterworks in Guangzhou (XT waterworks, NZ waterworks and XC waterworks) for subsequent disinfection byproducts extraction. XAD-2 128 macroporous resin was used to filtrate and enrich the CDBPs, and mixed organic solvents were used to elute. Dimethyl sulfoxide (DMSO) was used to fix the volume before being sent to laboratory. The specific operation was as follows: firstly, the newly purchased AmberLite XAD-2 macroporous resin was activated and soaked in $95 \%$ ethanol for $24 \mathrm{~h}$. It was washed with deionized water 5-6 times after soaking until 
the $\mathrm{pH}$ of the rinsing water was neutralized. The purified resin was loaded into the column, whose bottom was filled with glass wool. The peristaltic pump was used to slowly pump the water sample into the resin column at a flow rate of $30 \mathrm{~mL} / \mathrm{min}$ for filtration and enrichment. After filtration, the vacuum pump discharged the residual water in the resin column. The CDBPs concentrated on the resin were eluted with methanol and acetone $(1: 1 v / v)$. The resin was immersed in the eluent for $10 \mathrm{~min}$, then the eluent was slowly dropped and collected into the flask. Next, the eluent was concentrated to $1 \mathrm{~mL}$ in a rotary evaporator, and then dried in a stable nitrogen flow in a $0{ }^{\circ} \mathrm{C}$ water bath. We added dimethyl sulfoxide (DMSO) to dissolve and fix the volume to $10 \mathrm{~mL}$ after drying, then refrigerated it at $4{ }^{\circ} \mathrm{C}$. Two hundred liters of water samples were concentrated into four 10-mL samples for analysis. We chose trichloromethane, dibutyl phthalate, $\mathrm{N}$-nitroso dimethylamine, and $\mathrm{N}$-nitroso diethylamine as test items because they were feasible analytes for the testing center after combining with available analysis projects in reproductive toxicity and testing center (Guangdong Institute of Testing and Analysis).

\subsection{SCFAs Extraction and Concentration Detection}

The supernatant was used to extract the metabolite SCFAs after centrifugation. The extraction method of SCFAs was as follows: $1 \mathrm{~mL}$ ethyl ether and $200 \mu \mathrm{L} 50 \%$ concentrated sulfuric acid were added to the collected supernatant. The mixed solution was centrifuged at a low temperature of $4{ }^{\circ} \mathrm{C}$ at $6000 \times g \mathrm{rpm}$ for $10 \mathrm{~min}$. We prepared a new $2 \mathrm{~mL}$ EP tube during centrifugation, and added 2-3 anhydrous calcium chloride particles before labeling them. We collected the supernatant and transferred it to a new EP tube to remove excess water after centrifugation. Then, we delivered it to an injection vial followed by adding $10 \mu \mathrm{L} 250 \mu \mathrm{g} / \mathrm{mL}$ internal standard 2-ethylbutyric acid $10 \mu \mathrm{L}$ for subsequent GC/MS detection of SCFAs concentration. SCFAs standard curves were drawn according to previous studies, and GC/MS analysis was carried out in SIM mode. The initial temperature of the injector was maintained at $90^{\circ} \mathrm{C}$ for $1 \mathrm{~min}$. The temperature was increased at $15^{\circ} \mathrm{C} / \mathrm{min}$ to $120{ }^{\circ} \mathrm{C}$ for $30 \mathrm{~s}$, then increased at $15^{\circ} \mathrm{C} / \mathrm{min}$, and finally maintained at $180^{\circ} \mathrm{C}$ for $1 \mathrm{~min}$. The retention time of each short-chain fatty acid is: acetic acid (4.43 min), propionic acid (5.18 $\mathrm{min})$, isobutyric acid (5.42 $\mathrm{min})$, butyric acid (5.97 $\mathrm{min})$, iso-valeric acid (6.36 $\mathrm{min}$ ), valeric acid (6.99 $\mathrm{min})$, caproic acid (7.93 $\mathrm{min})$, and 2-ethyl butyric acid (7.10 $\mathrm{min})$

\subsection{Exposure of $C D B P$ In Vitro}

According to the measured concentration, the daily intake of CDBPs for residents is equal to daily drinking water $2000 \mathrm{~mL} \times$ detected concentration $(\mathrm{N})$. The corresponding compounds of chloroform and N-nitroso diethylamine at concentrations of $0.06 \mathrm{~g} / \mathrm{L}$ and $0.129 \mathrm{~g} / \mathrm{L}$, respectively, were added to the nutrient solution of the SHIME with a specific concentration of $X=$ Daily Intake $/(3 \times 200 \mathrm{~mL})$. Five times of the corresponding compound concentration was added for 14 days. Then, we analyzed the intestinal microbiota structure and the metabolism of SCFAs for each colonic intestinal flora by the same method as the experiment of Giuliani C and her team [35].

\subsection{Statistical Analysis}

The results were all expressed as mean \pm standard deviation. SPSS25.0 (Chicago, IL, USA) was used for all statistical analyses. Short-chain fatty acid concentrations were compared by $t$ test for two independent samples. One-way analysis of variance (ANOVA) was used to analyze the direct differences of each index in $\alpha$ diversity between the control group and the experimental group $(p<0.05)$.

\subsection{Data Deposition}

The microbial sequencing data were deposited into the repository of the National Center for Biotechnology Information (NCBI) under SRA accession number PRJNA728182. 


\section{Results}

\subsection{Quantitative Analysis of CDBPs in Treated Water}

To provide dose references for subsequent exposure experiments, we analyzed four concentrated water samples containing trichloromethane, dibutyl phthalate, nitrosodimethylamine, and N-nitrosodiethylamine. The concentrations of CDBPs detected in the water samples was listed in Table 1. Dibutyl phthalate and nitrosodimethylamine concentrations were below the detection limit. The chloroform concentrations from the three water sources were below $0.06 \mu \mathrm{g} / \mathrm{L}$, which were conformed to China's national standard range in drinking water (GB5749-2006). The concentrations of N-nitrosodiethylamine varied by water source. We therefore selected chloroform $\left(6 \times 10^{-2} \mu \mathrm{g} / \mathrm{L}\right)$ and N-nitrosodiethylamine $\left(1.29 \times 10^{-1} \mu \mathrm{g} / \mathrm{L}\right)$ as the exposure compounds.

Table 1. Detection concentration of CDBPs in water samples.

\begin{tabular}{|c|c|c|c|c|}
\hline $\begin{array}{l}\text { Analysis } \\
\text { Projects }\end{array}$ & Water Sample & $\begin{array}{c}\text { Detection } \\
\text { Result (mg/L) }\end{array}$ & $\begin{array}{l}\text { Detection Limit } \\
(\mathrm{mg} / \mathrm{L})\end{array}$ & $\begin{array}{l}\text { Detection } \\
\text { Method }\end{array}$ \\
\hline \multirow{4}{*}{ Chloroform } & $\mathrm{XT}$ & $3.4 \times 10^{-3}$ & \multirow{4}{*}{$2.5 \times 10^{-3}$} & \multirow{4}{*}{ HJ620-2011 } \\
\hline & $X C$ & $3.2 \times 10^{-3}$ & & \\
\hline & NZ & $3.6 \times 10^{-3}$ & & \\
\hline & Distilled water & $3.3 \times 10^{-3}$ & & \\
\hline \multirow{4}{*}{$\begin{array}{l}\text { Dibutyl } \\
\text { phthalate }\end{array}$} & XT & ND & \multirow{4}{*}{$1 \times 10^{-4}$} & \multirow{4}{*}{ HJ/T 72-2001 } \\
\hline & $X C$ & ND & & \\
\hline & NZ & ND & & \\
\hline & Distilled water & ND & & \\
\hline \multirow{4}{*}{$\begin{array}{c}\text { N-nitroso } \\
\text { dimethylamine }\end{array}$} & $\mathrm{XT}$ & ND & \multirow{4}{*}{$6 \times 10^{-4}$} & \multirow{4}{*}{ HJ 809-2016 } \\
\hline & $\mathrm{XC}$ & ND & & \\
\hline & NZ & ND & & \\
\hline & Distilled water & ND & & \\
\hline \multirow{4}{*}{$\begin{array}{c}\text { N-nitroso } \\
\text { diethylamine }\end{array}$} & XT & $7.7 \times 10^{-3}$ & \multirow{4}{*}{$5 \times 10^{-4}$} & \multirow{4}{*}{ HJ 809-2016 } \\
\hline & $\mathrm{XC}$ & $2.8 \times 10^{-3}$ & & \\
\hline & NZ & $7.0 \times 10^{-3}$ & & \\
\hline & Distilled water & $7.7 \times 10^{-3}$ & & \\
\hline
\end{tabular}

ND: Not Detected. The concentration was below the detection limit and was not detected.

\subsection{Health Effects of CDBPs on Intestinal Microbe Diversity in the SHIME Model}

The abundance of operational taxonomic units was shown in Figure 1. At the phylum level (Figure 1A), the abundance of Actinobacteria decreased in the transverse colon and descending colon, but increased in the ascending colon. The abundance of Proteobacteria increased in the ascending colon and descending colon, but decreased in the transverse colon. Analogously, the abundance of Firmicutes in the ascending colon and descending colon decreased after the exposure to CDBPs. Moreover, the abundance of Bacteroidetes and Lentisphaerae decreased significantly in the descending colon, while the abundance of Synergistetes increased. Notably, the abundance of Fusobacteria decreased throughout the experiment, but increased in TCC2. At the genus level (Figure 1B), the abundance of Lachnospiraceae members, Bilophila, Oscillospira, Parabacteroides, Desulfovibrio, and Roseburia increased in the ascending colon, while that of Sutterella, Bacteroides, Escherichia, Phascolarctobacterium, Clostridium, Citrobacter, and Klebsiella increased in the descending colon. 


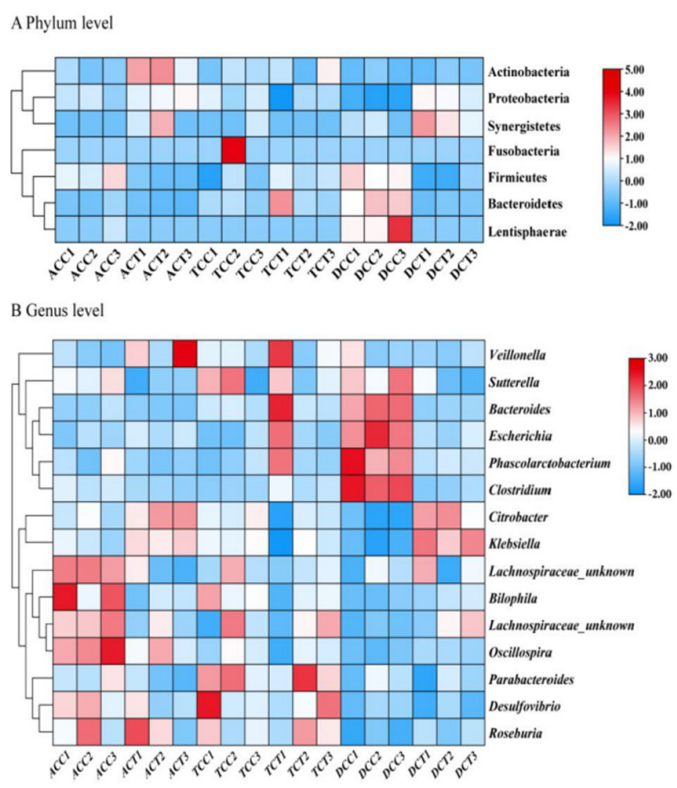

Figure 1. Heat maps of the relative abundance of major phylum (A) and genera (B) levels found in the gut microbiota in SHIME. (The first two letters AC: Ascending colon; TC: Transverse colon; DC: Descending colon; the third letter C: Control group; T: Treatment group.).

\subsection{Health Effects of CDBPs on the Structure of Intestinal Bacteria in the SHIME Model}

To assess the diversity differences between the control group and the experimental group, we analyzed samples from the colon segments of the SHIME model at the operational taxonomic unit level to identify changes in evenness (Shannon index) and abundance ( $\beta$ diversity index) (Figure 2A,B). We found a statistical difference in the Shannon index of samples from both the ascending colon and descending colon before and after exposure $(p<0.05)$ with no difference in the transverse colon. The Chao 1 index of diversity did not differ before and after any intracolonic exposure. In terms of abundance ( $\beta$ diversity index), principal coordinate analysis showed that the members of each group were dispersed without significant aggregation (Figure 2C), indicating that there was no statistically significant difference in $\beta$-diversity before and after exposure $(p>0.05)$.
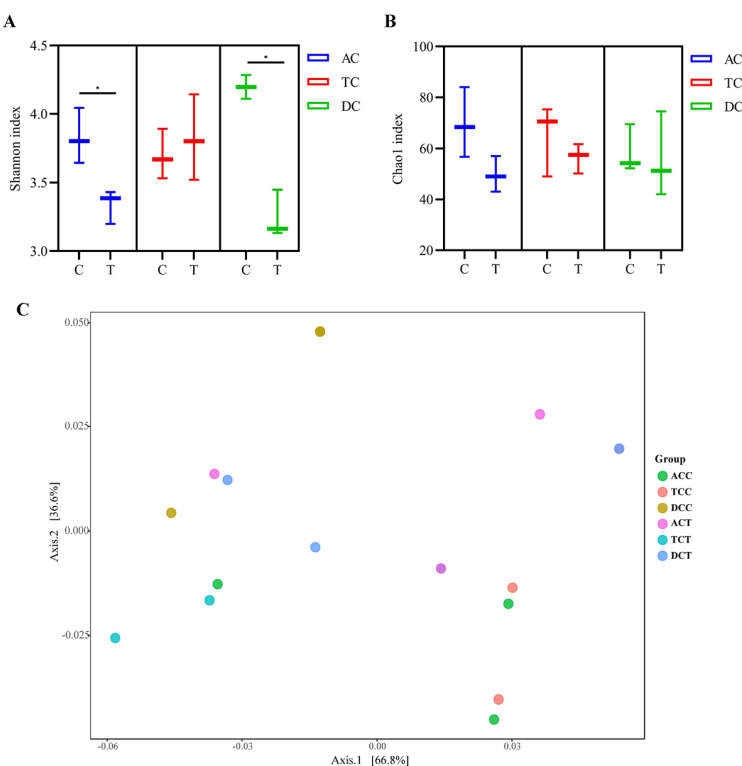

Figure 2. Shannon index (A) and Chao 1 lndex (B) of $\alpha$ diversity and PCoA analysis of $\beta$ diversity (C) between control group and treatment group. (The first two letters AC: Aascending colon; TC: Transverse colon; DC: Descending colon; the third letter C: Control group; T: Treatment group.). 
The abundance of Bilophila, Lachnospiraceae members, Oscillospira, and Desulfovibrio were increased after exposing in the ascending colon (Figure 2). The abundance of Veillonella, Citrobacter, and Klebsiella decreased after the exposure in the ascending colon. Interestingly, the abundance after the last three days of exposure was consistent with that before exposure. In TCT1 and TCT2, we observed obvious changes, such as an increase in the abundance of Phascolarctobacterium, Clostridium, Bacteroides, and Escherichia. In addition, the abundance of the intestinal microbes Sutterella, Phascolarctobacterium, Clostridium, Bacteroides, and Escherichia in the descending colon decreased substantially after combining exposure, while the abundance of Citrobacter and Klebsiella was increased (Figure 2).

\subsection{Health Effects of CDBPS on SCFA Production by Intestinal Flora in the SHIME Model}

To evaluate the potential effects of CDBPs on SCFAs in intestinal microbes, the samples extracted from the SHIME were analyzed for acetic acid, propionic acid, butyric acid, isobutyric acid, valeric acid, isovaleric acid, and caproic acid (Figure 3). The concentrations of acetic acid, propionic acid, butyric acid, and total SCFAs were analyzed in detail to infer potential adverse effects on human health from disinfection byproducts. Compared with levels in the transverse colon and descending colon, the levels of isobutyric acid, valeric acid, isobutyric acid, and caproic acid were distinctly lower in the ascending colon. Acetic acid, propionic acid, and butyric acid were dominant in the ascending colon, and the proportion of propionic acid was higher than the proportion in the transverse colon and descending colon. However, there was no overall difference in the proportion of SCFAs before and after exposure.

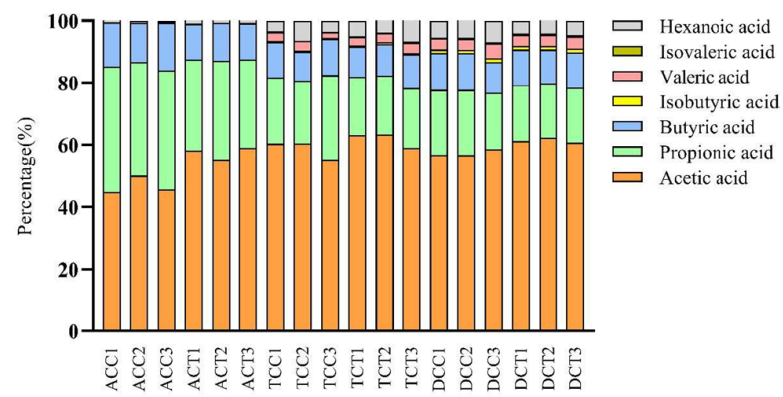

Figure 3. Composition profiles of seven SCFAs in SHIME. (The first two letters AC: Ascending colon; TC: Transverse colon; DC: Descending colon; the third letter C: Control group; T: Treatment group.).

SCFA concentrations decreased after the exposure, especially those of propionic acid (Figure 4). Before exposure, concentrations of propionic acid in the ascending colon, transverse colon, and descending colon were $178.93 \pm 47.62,124.32 \pm 94.21$, and $84.24 \pm 27.90 \mu \mathrm{g} / \mathrm{mL}$, respectively. After exposure, the concentrations of propionic acid were $106.68 \pm 13.45$, $55.42 \pm 33.57$, and $50.76 \pm 9.67 \mu \mathrm{g} / \mathrm{mL}$, respectively. Similar downward trends were observed in the concentrations of acetic acid, butyric acid, and overall SCFA levels, but these decreases did not reach statistical significance ( $p>0.05$, independent samples $t$-test). In general, trichloromethane and N-nitrosodiethylamine tended to inhibit SCFAs in the SHIME intestinal flora model, but the alterations were indistinct. 

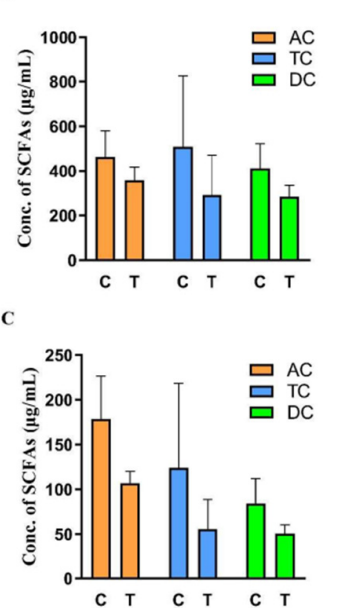
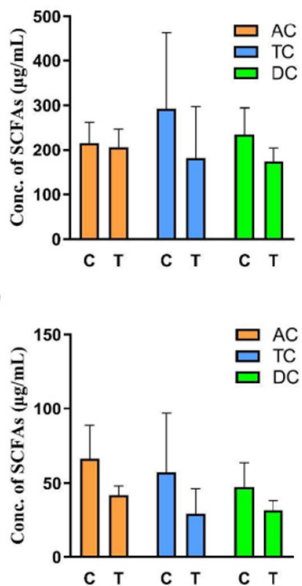

Figure 4. Concentration of total SCFAs and major SCFAs in SHIME. (A) total SCFAs; (B) acetic acid; (C) propionic acid; (D) butyric acid.

\section{Discussion}

Disinfection eliminates waterborne pathogens, preventing infectious diseases. Most waterworks currently use chlorination disinfection to treat water [36-38], but the processes typically produce CDBPs, which may exert adverse health effects [6]. Previous studies have shown that exposure to certain CDBPs can adversely damage the reproductive system and immune system [6-11], and haloacetic acid can injure the DNA of rat ovarian cells [12]. Over the past 50 years, attention has focused on the formation of toxic, carcinogenic, mutagenic, and teratogenic chlorination disinfection byproducts [39]. As is known to all, the gut microbiota maintains organismal health [40,41]. However, little is known about the digestive impact of CDBPs and gut microbiota. To investigate the influence of CDBPs on intestinal microbes, we used the in vitro SHIME model to study the effects of one single-dose subacute exposure of environmental pollutants on human intestinal microbes. To our knowledge, this is the first SHIME-based analysis of CDBPs and intestinal flora. We found that the combination of chloroform and N-nitrosodiethylamine can affect the structure of intestinal flora, including Citrobacter and Klebsiella [42]. The former is Gram-negative, which can infect immunocompromised patients, and the latter can cause iatrogenic infections and pneumonia $[43,44]$. Therefore, it is reasonable to speculate that alterations in the relative abundances of intestinal microbes can affect health. The methods used in this study are similar to the methods used in the study of antibiotics and probiotics in the SHIME model, involving a direct exposure via the simulated nutrient solution.

The exposure reduced the abundance of Firmicutes and Bacteroidetes, which account for more than $80 \%$ of the intestinal microbes, showing that CDBPs in drinking water can change the human intestinal microbiome. The alteration was not obvious owing to the low concentrations of chloroform and N-nitrosodiethylamine. The reductions in SCFAs were minimal, which are attributable to the reductions in the abundance of Firmicutes and Bacteroidetes. Firmicutes are the main producers of butyric acid [45] and Bacteroidetes are the main producers of acetic acid and propionic acid [45,46]. For example, Clostridium (Firmicutes) is known to produce butyric acid [47], and the decrease in microbial abundance can explain the reductions in SCFAs. SCFAs interact with metabolite-sensitive G proteincoupled receptors GPR41, GPR43, and GPR109A, which are expressed by the intestinal epithelium and immune cells, to maintain homeostasis in the intestinal tract and other organs $[48,49]$. Low concentrations of the CDBPs dichloroacetonitrile in drinking water have been shown to dysregulate the gut microbiome and metabolic profile in rats [50], and the CDBPs dichloroacetamide was reported to alter the intestinal flora of adult zebrafish [51]. These findings, which agree with ours, demonstrate the health impact of disinfection byproducts on the intestinal flora. 
It should be noted that we inevitably have some limitations in our study. First, we used only a low-concentration exposure in this study, making our results not suitable when exposed to high concentrations of CDBPs. Furthermore, because of the differences between species and exposure patterns [52], our experimental results were not generalizable to the actual human health in vivo situation. In addition, considering the realistic conditions, we investigated only four compounds, while drinking water contains various CDBPs [53]. Finally, ingestion from drinking water is just one of the ways of exposure to CDBPs, while actual intake may be substantially greater than our estimates. Further relative studies are thus urgently needed. Despite these potential limitations, to our knowledge, this is the first study to demonstrate the feasibility of applying the SHIME model. It explored the intestinal toxicity of chlorinated byproducts to the gut microbiome as well as the mechanism underlying the effect of CDBPs on the intestinal flora. The findings of this study can improve our understanding of the health impact of CDBPs on the intestinal flora and call for better control of CDBPs in treated water.

\section{Conclusions}

The intervention of CDBPs can both alter the diversity of intestinal flora and adjust the abundance level of it. Exposure to chloroform and N-nitrosodiethylamine can affect the intestinal microbial structure in the SHIME system, especially in the descending colon. The abundance of Sutterella, Phascolarctobacterium, Clostridium, Bacteroides, and Escherichia decreased, while Citrobacter and Klebsiella increased. The exposure down regulated the production of SCFAs by the gut microflora in a manner commensurate with the reduction in the abundance of microbial species that produce these SCFAs. Our study indicates the feasibility of applying the SHIME model to studying the health effects of intestinal toxicity of chlorinated byproducts to the gut microbiome and calls for attention to the health impact of CDBPs on intestinal flora.

Author Contributions: Conceptualization, D.W. (Dong Wang) and Z.W.; Data curation, X.L. and L.S.; Formal analysis, D.W. (Dong Wang) and D.W. (Di Wu); Investigation, S.L., Q.L. and J.Z.; Methodology, Y.J. and Z.W.; Project administration, D.W. (Dong Wang), L.Z. and W.H.; Resources, D.W. (Dong Wang), S.L., Z.W., Y.Z., L.Z. and C.G.; Software, Y.J., Z.W. and X.L.; Supervision, Y.Z. and W.H.; Validation, D.W. (Dong Wang), Y.J., D.W. (Di Wu), L.Z. and L.S.; Visualization, Y.J. and Z.W.; Writingoriginal draft, D.W. (Dong Wang), Y.J. and Z.W.; Writing-review and editing, Y.J. and D.W. (Di Wu). All authors have read and agreed to the published version of the manuscript.

Funding: The studies described in this manuscript were performed at the request of and funded by the Science and Technology Program of Guangzhou (201904010161); Guangzhou Municipal Science and Technology Project (20191A011063).

Institutional Review Board Statement: The study was conducted in accordance with the Declaration of Helsinki, and approved by the Ethics Committee of Guangzhou Center for Disease Control and Prevention (protocol code GZCDC 2018013, approval date 23 May 2018).

Informed Consent Statement: Informed consent was obtained from all subjects involved in the study.

Data Availability Statement: The microbial sequencing data have been deposited into the National Center for Biotechnology Information (NCBI) under SRA accession number PRJNA 718202.

Acknowledgments: This work was supported by the Science and Technology Program of Guangzhou (201904010161); Guangzhou Municipal Science and Technology Project (20191A011063).

Conflicts of Interest: The authors declare that they have no conflict of interest in this paper and the manuscript is approved by all authors for publication.

\section{References}

1. Alexandrou, L.; Meehan, B.J.; Jones, O.A.H. Regulated and emerging disinfection by-products in recycled waters. Sci. Total Environ. 2018, 637-638, 1607-1616. [CrossRef] [PubMed]

2. Tak, S.; Kumar, A. Chlorination disinfection by-products and comparative cost analysis of chlorination and UV disinfection in sewage treatment plants: Indian scenario. Environ. Sci. Pollut. Res. Int. 2017, 24, 26269-26278. [CrossRef] [PubMed] 
3. Sirivedhin, T.; Gray, K.A. 2. Comparison of the disinfection by-product formation potentials between a wastewater effluent and surface waters. Water Res. 2005, 39, 1025-1036. [CrossRef] [PubMed]

4. Lu, J.; Zhang, T.; Ma, J.; Chen, Z. Evaluation of disinfection by-products formation during chlorination and chloramination of dissolved natural organic matter fractions isolated from a filtered river water. J. Hazard Mater. 2009, 162, 140-145. [CrossRef]

5. Burch, J.B.; Everson, T.M.; Seth, R.K.; Wirth, M.D.; Chatterjee, S. Trihalomethane exposure and biomonitoring for the liver injury indicator, alanine aminotransferase, in the United States population (NHANES 1999-2006). Sci. Total Environ. 2015, 521-522, 226-234. [CrossRef]

6. Krasner, S.W. The formation and control of emerging disinfection by-products of health concern. Philos. Trans. A. Math. Phys. Eng. Sci. 2009, 367, 4077-4095. [CrossRef]

7. Grellier, J.; Bennett, J.; Patelarou, E.; Smith, R.B.; Toledano, M.B.; Rushton, L.; Briggs, D.J.; Nieuwenhuijsen, M.J. Exposure to disinfection by-products, fetal growth, and prematurity: A systematic review and meta-analysis. Epidemiology 2010, 21, 300-313. [CrossRef]

8. Wellejus, A.; Dalgaard, M.; Loft, S. Oxidative DNA damage in male Wistar rats exposed to di-n-butyl phthalate. J. Toxicol. Environ. Health A 2002, 65, 813-824. [CrossRef]

9. Rajaguru, P.; Vidya, L.; Baskarasethupathi, B.; Kumar, P.A.; Palanivel, M.; Kalaiselvi, K. Genotoxicity evaluation of polluted ground water in human peripheral blood lymphocytes using the comet assay. Mutat. Res. 2002, 517, 29-37. [CrossRef]

10. Zhang, Y.; Jiang, L.; Jiang, L.; Geng, C.; Li, L.; Shao, J.; Zhong, L. Possible involvement of oxidative stress in potassium bromate-induced genotoxicity in human HepG2 cells. Chem. Biol. Interact. 2011, 189, 186-191. [CrossRef]

11. Le Roux, J.; Plewa, M.J.; Wagner, E.D.; Nihemaiti, M.; Dad, A.; Croue, J.P. Chloramination of wastewater effluent: Toxicity and formation of disinfection byproducts. J. Environ. Sci. 2017, 58, 135-145. [CrossRef] [PubMed]

12. Komaki, Y.; Pals, J.; Wagner, E.D.; Marinas, B.J.; Plewa, M.J. Mammalian cell DNA damage and repair kinetics of monohaloacetic acid drinking water disinfection by-products. Environ. Sci. Technol. 2009, 43, 8437-8442. [CrossRef] [PubMed]

13. Chaves, R.S.; Guerreiro, C.S.; Cardoso, V.V.; Benoliel, M.J.; Santos, M.M. Toxicological assessment of seven unregulated drinking water Disinfection By-products (DBPs) using the zebrafish embryo bioassay. Sci. Total Environ. 2020, 742, 140522. [CrossRef] [PubMed]

14. Bu, L.; Zhou, S.; Zhu, S.; Wu, Y.; Duan, X.; Shi, Z.; Dionysiou, D.D. Insight into carbamazepine degradation by UV/monochloramine: Reaction mechanism, oxidation products, and DBPs formation. Water Res. 2018, 146, $288-297$. [CrossRef] [PubMed]

15. Li, Y.; Jiang, J.; Li, W.; Zhu, X.; Zhang, X.; Jiang, F. Volatile DBPs contributed marginally to the developmental toxicity of drinking water DBP mixtures against Platynereis dumerilii. Chemosphere 2020, 252, 126611. [CrossRef] [PubMed]

16. Ohe, T.; Watanabe, T.; Wakabayashi, K. Mutagens in surface waters: A review. Mutat. Res. 2004, 567, 109-149. [CrossRef] [PubMed]

17. Guan, Y.; Wang, X.; Wong, M.; Sun, G.; An, T.; Guo, J.; Zhang, G. Evaluation of Genotoxic and Mutagenic Activity of Organic Extracts from Drinking Water Sources. PLoS ONE 2017, 12, e0170454. [CrossRef]

18. Hung, S.; Mohan, A.; Reckhow, D.A.; Godri Pollitt, K.J. Assessment of the in vitro toxicity of the disinfection byproduct 2,6-dichloro-1,4-benzoquinone and its transformed derivatives. Chemosphere 2019, 234, 902-908. [CrossRef]

19. Morrison, D.J.; Preston, T. Formation of short chain fatty acids by the gut microbiota and their impact on human metabolism. Gut Microbes. 2016, 7, 189-200. [CrossRef]

20. Ma, Q.; Li, Y.; Li, P.; Wang, M.; Wang, J.; Tang, Z.; Wang, T.; Luo, L.; Wang, C.; Wang, T.; et al. Research progress in the relationship between type 2 diabetes mellitus and intestinal flora. Biomed. Pharmacother. 2019, 117, 109138. [CrossRef]

21. Yan, X.; Jin, J.; Su, X.; Yin, X.; Gao, J.; Wang, X.; Zhang, S.; Bu, P.; Wang, M.; Zhang, Y.; et al. Intestinal Flora Modulates Blood Pressure by Regulating the Synthesis of Intestinal-Derived Corticosterone in High Salt-Induced Hypertension. Circ. Res. 2020, 126, 839-853. [CrossRef] [PubMed]

22. Wu, Y.R.; Kuang, G.Y.; Lu, F.G.; Wang, H.X.; Lu, M.; Zhou, Q. Pathological Relationship between Intestinal Flora and Osteoarthritis and Intervention Mechanism of Chinese Medicine. Chin. J. Integr. Med. 2019, 25, 716-720. [CrossRef] [PubMed]

23. Chen, W.; Lu, J.; Jiang, S.Y.; Zhao, K.D.; Duan, D.F. In Situ Carbon Isotope Analysis by Laser Ablation MC-ICP-MS. Anal. Chem. 2017, 89, 13415-13421. [CrossRef] [PubMed]

24. Chen, L.; Zhang, W.; Hua, J.; Hu, C.; Lok-Shun Lai, N.; Qian, P.Y.; Lam, P.K.S.; Lam, J.C.W.; Zhou, B. Dysregulation of Intestinal Health by Environmental Pollutants: Involvement of the Estrogen Receptor and Aryl Hydrocarbon Receptor. Environ. Sci. Technol. 2018, 52, 2323-2330. [CrossRef] [PubMed]

25. Chen, L.; Guo, Y.; Hu, C.; Lam, P.K.S.; Lam, J.C.W.; Zhou, B. Dysbiosis of gut microbiota by chronic coexposure to titanium dioxide nanoparticles and bisphenol A: Implications for host health in zebrafish. Environ. Pollut. 2018, 234, 307-317. [CrossRef]

26. Jin, Y.; Xia, J.; Pan, Z.; Yang, J.; Wang, W.; Fu, Z. Polystyrene microplastics induce microbiota dysbiosis and inflammation in the gut of adult zebrafish. Environ. Pollut. 2018, 235, 322-329. [CrossRef]

27. Choi, J.J.; Eum, S.Y.; Rampersaud, E.; Daunert, S.; Abreu, M.T.; Toborek, M. Exercise attenuates PCB-induced changes in the mouse gut microbiome. Environ. Health Perspect. 2013, 121, 725-730. [CrossRef]

28. Zhang, L.; Nichols, R.G.; Correll, J.; Murray, I.A.; Tanaka, N.; Smith, P.B.; Hubbard, T.D.; Sebastian, A.; Albert, I.; Hatzakis, E.; et al. Persistent Organic Pollutants Modify Gut Microbiota-Host Metabolic Homeostasis in Mice through Aryl Hydrocarbon Receptor Activation. Environ. Health Perspect. 2015, 123, 679-688. [CrossRef] 
29. Zhang, Y.; Zhao, F.; Deng, Y.; Zhao, Y.; Ren, H. Metagenomic and metabolomic analysis of the toxic effects of trichloroacetamideinduced gut microbiome and urine metabolome perturbations in mice. J. Proteome Res. 2015, 14, 1752-1761. [CrossRef]

30. Zhu, J.; Kong, Y.; Yu, J.; Shao, S.; Mao, M.; Zhao, M.; Yue, S. Consumption of drinking water N-Nitrosamines mixture alters gut microbiome and increases the obesity risk in young male rats. Environ. Pollut. 2019, 248, 388-396. [CrossRef]

31. Verhoeckx, K.; Cotter, P.; López-Expósito, I.; Kleiveland, C.; Lea, T.; Mackie, A.; Requena, T.; Swiatecka, D.; Wichers, H. The Impact of Food Bioactives on Health: In Vitro and Ex Vivo Models; Springer: Cham, Switzerland, 2019; p. 24.

32. Giuliani, C.; Marzorati, M.; Daghio, M.; Franzetti, A.; Innocenti, M.; Van de Wiele, T.; Mulinacci, N. Effects of Olive and Pomegranate By-Products on Human Microbiota: A Study Using the SHIME((R)) in Vitro Simulator. Molecules 2019, $24,3791$. [CrossRef] [PubMed]

33. Joly, C.; Gay-Queheillard, J.; Leke, A.; Chardon, K.; Delanaud, S.; Bach, V.; Khorsi-Cauet, H. Impact of chronic exposure to low doses of chlorpyrifos on the intestinal microbiota in the Simulator of the Human Intestinal Microbial Ecosystem (SHIME) and in the rat. Environ. Sci. Pollut. Res. Int. 2013, 20, 2726-2734. [CrossRef] [PubMed]

34. Yu, H.; Wu, B.; Zhang, X.X.; Liu, S.; Yu, J.; Cheng, S.; Ren, H.Q.; Ye, L. Arsenic Metabolism and Toxicity Influenced by Ferric Iron in Simulated Gastrointestinal Tract and the Roles of Gut Microbiota. Environ. Sci. Technol. 2016, 50, 7189-7197. [CrossRef] [PubMed]

35. Giuliani, C.; Marzorati, M.; Innocenti, M.; Vilchez-Vargas, R.; Vital, M.; Pieper, D.H.; Van de Wiele, T.; Mulinacci, N. Dietary supplement based on stilbenes: A focus on gut microbial metabolism by the in vitro simulator M-SHIME(R). Food Funct. 2016, 7, 4564-4575. [CrossRef] [PubMed]

36. Pereira, V.J.; Marques, R.; Marques, M.; Benoliel, M.J.; Barreto Crespo, M.T. Free chlorine inactivation of fungi in drinking water sources. Water Res. 2013, 47, 517-523. [CrossRef] [PubMed]

37. Simoes, L.C.; Simoes, M.; Vieira, M.J. Influence of the diversity of bacterial isolates from drinking water on resistance of biofilms to disinfection. Appl. Environ. Microbiol. 2010, 76, 6673-6679. [CrossRef]

38. Luh, J.; Marinas, B.J. Inactivation of Mycobacterium avium with free chlorine. Environ. Sci. Technol. 2007, 41, 5096-5102. [CrossRef]

39. Henao, L.D.; Turolla, A.; Antonelli, M. Disinfection by-products formation and ecotoxicological effects of effluents treated with peracetic acid: A review. Chemosphere 2018, 213, 25-40. [CrossRef]

40. Gerritsen, J.; Smidt, H.; Rijkers, G.T.; De Vos, W.M. Intestinal microbiota in human health and disease: The impact of probiotics. Genes Nutr. 2011, 6, 209-240. [CrossRef]

41. Marteau, P. The clinical importance of intestinal microbiota. Gastroenterol. Clin. Biol. 2010, 34 (Suppl. 1), S93-S97. [CrossRef]

42. Oyeka, M.; Antony, S. Citrobacter braakii Bacteremia: Case Report and Review of the Literature. Infect. Disord. Drug Targets 2017, 17, 59-63. [CrossRef] [PubMed]

43. Rodriguez-Medina, N.; Barrios-Camacho, H.; Duran-Bedolla, J.; Garza-Ramos, U. Klebsiella variicola: An emerging pathogen in humans. Emerg. Microbes Infect. 2019, 8, 973-988. [CrossRef]

44. Herridge, W.P.; Shibu, P.; O'Shea, J.; Brook, T.C.; Hoyles, L. Bacteriophages of Klebsiella spp., their diversity and potential therapeutic uses. J. Med. Microbiol. 2020, 69, 176-194. [CrossRef] [PubMed]

45. Louis, P.; Flint, H.J. Formation of propionate and butyrate by the human colonic microbiota. Environ. Microbiol. 2017, 19, 29-41. [CrossRef]

46. Riviere, A.; Selak, M.; Lantin, D.; Leroy, F.; De Vuyst, L. Bifidobacteria and Butyrate-Producing Colon Bacteria: Importance and Strategies for Their Stimulation in the Human Gut. Front. Microbiol. 2016, 7, 979. [CrossRef]

47. Huang, J.; Tang, W.; Zhu, S.; Du, M. Biosynthesis of butyric acid by Clostridium tyrobutyricum. Prep. Biochem. Biotechnol. 2018, 48, 427-434. [CrossRef] [PubMed]

48. Tan, J.; McKenzie, C.; Potamitis, M.; Thorburn, A.N.; Mackay, C.R.; Macia, L. The role of short-chain fatty acids in health and disease. Adv. Immunol. 2014, 121, 91-119. [CrossRef] [PubMed]

49. Sivaprakasam, S.; Prasad, P.D.; Singh, N. Benefits of short-chain fatty acids and their receptors in inflammation and carcinogenesis Pharmacol. Ther. 2016, 164, 144-151. [CrossRef]

50. Xue, B.; Li, C.; Wang, S.; Zhao, C.; Dai, K.; Li, W.; Xi, Z.; Wang, J.; Qiu, Z.; Shen, Z. Effects of 2,2-dichloroacetamide (DCAcAm), an emerging disinfection by-product in drinking water, on the intestinal microbiota of adult zebrafish. J. Water Health 2019, 17, 683-690. [CrossRef] [PubMed]

51. Xue, B.; Dai, K.; Zhang, X.; Wang, S.; Li, C.; Zhao, C.; Yang, X.; Xi, Z.; Qiu, Z.; Shen, Z.; et al. Low-concentration of dichloroacetonitrile (DCAN) in drinking water perturbs the health-associated gut microbiome and metabolic profile in rats. Chemosphere 2020, 258, 127067. [CrossRef] [PubMed]

52. Liu, L.; Firrman, J.; Tanes, C.; Bittinger, K.; Thomas-Gahring, A.; Wu, G.D.; Van den Abbeele, P.; Tomasula, P.M. Establishing a mucosal gut microbial community in vitro using an artificial simulator. PLoS ONE 2018, 13, e0197692. [CrossRef] [PubMed]

53. Zhang, L.; Xu, L.; Zeng, Q.; Zhang, S.H.; Xie, H.; Liu, A.L.; Lu, W.Q. Comparison of DNA damage in human-derived hepatoma line (HepG2) exposed to the fifteen drinking water disinfection byproducts using the single cell gel electrophoresis assay. Mutat. Res. 2012, 741, 89-94. [CrossRef] [PubMed] 